EFFECT OF HEATING RATE ON THE THERMODYNAMIC PROPERTIES OF PULVERIZED COAL 


\section{EFFECT OF HEATING RATE ON THE THERMODYNAMIC PROPERTIES OF PULVERIZED COAL}

Semi-Annual Progress Report

For the Period March 24, 1999 to September 24, 1999

Ramanathan Sampath (Principal Investigator)

October 1999

Grant No. DE-FG22-96PC96224

For

AAD Document Control

U.S. Department of Energy

Federal Energy Technology Center

P.O. Box 10940, MS 921-143

Pittsburgh, PA 15236-0940

By

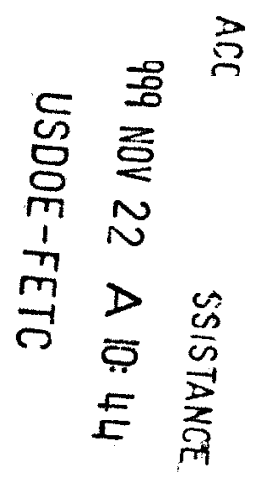

Department of Engineering

Clark Atlanta University

Atlanta. GA 30314 


\section{DISCLAIMER}

This report was prepared as an account of work sponsored by an agency of the United States Government. Neither the United States Government nor any agency thereof, nor any of their employees, makes any warranty, express or implied, or assumes any legal liability or responsibility for the accuracy, completeness, or usefulness of any information, apparatus, product, or process disclosed, or represents that its use would not fringe privately owned rights. Reference herein to any specific commercial product, process, or service by trade name, trademark, manufacturers, or otherwise does not necessarily constitute or imply its endorsement, recommendation, or favoring by the United States Government or any agency thereof. The views and opinions of authors expressed herein do not necessarily state or reflect those of the United States Government or any agency thereof. 


\title{
EFFECT OF HEATING RATE ON THE THERMODYNAMIC PROPERTIES OF PULVERIZED COAL
}

\begin{abstract}
This semi-annual technical progress report describes work performed under DOE Grant No. DE-FG22-96PC96224 during the period March 24, 1999 to September 23, 1999 which covers the last (sixth) six months of the project. During this reporting period, extraction of devolatilization timescales and temperature data at these time-scales analyzing the high-speed films taken during the experiments was complete. Also a new thermodynamic model was developed to predict the heat transfer behavior for coal particles subjected to a range of heating rates using one approach based on the analogy of polymers. Sensitivity analyses of this model suggest that bituminous coal particles behave like polymers during rapid heating on the order of $10^{4}-10^{7} \mathrm{~K} / \mathrm{s}$. At these heating rates during the early stages within the first few milliseconds of heating time, the vibrational part of the heat capacity of the coal molecules appears to be still frozen but during the transition from heat-up to devolatization, the heat capacity appears to attain a sudden jump in its value as in the case of polymers. There are few data available in the coal literature for $10^{2}-10^{3} \mathrm{~K} / \mathrm{s}$ obtained by UTRC in their previous studies. These data were obtained for a longer heating duration on the order of several seconds as opposed to the 10 milliseconds heating time in the single particle experiments discussed above. The polymer analogy model is being modified to include longer heating time on the order of several seconds to test these data. It is expected that the model might still do a good job in the case of these larger heating time but very low heating rate experiments. Completion of the numerical analysis of the experimental data and preparation of the final report are in progress.
\end{abstract}




\section{TABLE OF CONTENTS}

page

ABSTRACT...............

EXECUTIVE SUMMARY .................................................................. 1

INTRODUCTION .......................................................................... 2

PROGRESS TO DATE ............................ 2

OUTCOMES TO DATE........................... 5

WORK PERFORMED DURING THIS PERIOD......................................... 6

PLANS FOR THE NEXT REPORTING PERIOD....................... 8

SUMMARY AND CONCLUSIONS.......................................................... 8

$\begin{array}{ll}\text { ACKNOWLEDGMENTS. } & 8\end{array}$

REFERENCES......................... 8 


\section{EXECUTIVE SUMMARY}

In this semi-annual report, the work performed under DOE Grant No. DE-FG22-96PC96224 during the period March 24, 1999 to September 23, 1999 is described and the major accomplishments are highlighted summarizing the most important research results.

In all major coal conversion processes, coal undergoes a devolatilization stage while it is heated to the reaction temperature. The recent experimental studies of devolatilization of pulverized coal at rapid heating rates representative of coal combustors have greatly improved our general understanding of this process. But the heat transfer analysis with commonly-applied thermal properties developed from slow heating rate experiments did not predict either the early heating or the latter stages of heating. Knowledge of the role of heating rate on coal thermal properties is essential to progress in advanced coal utilization technology.

The objectives of this project are to understand the effect of heating rate on thermal properties of pulverized coal particles. The specific objectives are to subject coal particles into a broad range of heating rates, measure temperature histories, and develop thermal property (heat capacity and thermal conductivity) data that predict the measured temperature histories.

Experiments and modeling are being carried out to meet the project objectives. The successful accomplishment of the above goals will enhance our understanding of coal thermal properties and hence progress towards advanced combustion modeling.

Collection and reduction of experimental data for a total of 28 single coal particles using the Single Particle Laboratory, FETC's Morgantown facility was completed during this reporting period. Also a new thermodynamic model was developed to predict the heat transfer behavior for coal particles subjected to a range of heating rates using one approach based on the analogy of polymers. Sensitivity analyses of this model suggest that bituminous coal particles behave like polymers during rapid heating on the order of $10^{4}-10^{7} \mathrm{~K} / \mathrm{s}$. At these heating rates during the early stages within the first few milliseconds of heating time, the vibrational part of the heat capacity of the coal molecules appears to be still frozen but during the transition from heat-up to devolatization, the heat capacity appears to attain a sudden jump in its value as in the case of polymers. There are few data available in the coal literature for $10^{2}-10^{3} \mathrm{~K} / \mathrm{s}$ obtained by UTRC in their previous studies. These data were obtained for a longer heating duration on the order of several seconds as opposed to the 10 milliseconds heating time in the single particle experiments discussed above. The polymer analogy model is being modified to include longer heating time on the order of several seconds to test these data. It is expected that the model might still do a good job in the case of these larger heating time but very low heating rate experiments. Completion of the numerical analysis of the experimental data and preparation of the final report are in progress. 


\section{INTRODUCTION}

This semi-annual technical progress report describes work performed under DOE Grant No. DE-FG22-96PC96224 during the period September 24, 1998 to March 23, 1999 which covers the last six months of the project.

In all major coal conversion processes, coal undergoes a devolatilization stage while it is heated to the reaction temperature. Recent experimental studies of devolatilization of pulverized coal at rapid heating rates representative of coal combustors have greatly improved our general understanding of this process [1-18]. But the heat transfer analysis with commonly-applied thermal properties developed from slow heating rate experiments did not predict either the early heating or the latter stages of heating [1-3,18-19]. Design of coal combustion and conversion processes require knowledge of thermal properties to construct an energy balance. It is accepted that there are uncertainties in the heat capacity of coal especially for the high heating rate studies $[2,6]$. It is also accepted that the large thermal gradients within the particle (due to thermal conductivity of coal) make prediction of the temperature difficult during the early heating in these studies [6]. However, there has been no independent study conducted to investigate the effect of heating rate on the thermal properties of coal particles. Knowledge of the role of heating rate on coal thermal properties is essential to progress in advanced coal utilization technology.

The objectives of this proposal are to understand the effect of heating rate on thermal properties of pulverized coal particles. The specific objectives are:

1) Subject coal particles into a broad range of heating rates and extract heat capacity information for high heating rate applications.

2) Also develop thermal conductivity information for coal particles subjected to rapid heating rates representative of coal combustors.

Experiments and modeling are being carried out to meet the project objectives. The successful accomplishment of the above goals will provide better understanding of coal thermal properties in high heating rate applications and hence improved combustion modeling.

\section{PROGRESS TO DATE}

Literature articles [1-45] were reviewed to understand the effect of heating rate on various parameters of a coal particle. The role of heating rate on the onset of volatile evolution, volatile yield, product composition to a lesser extent, coal type and particle size were found to be well established. As heating becomes more rapid, the onset of devolatilization shifts to much smaller time scales and to much higher surface temperatures [2,18-19]. However, the role of heating rate on coal thermal properties was not found to be well understood. Previous results clearly demonstrated that particle temperature-dependent thermal property assumptions routinely applied in coal combustion models result in large errors (up to 100 percent) in calculated temperature histories [2,18-19]. 
Remote access from CAU to the VAX/VMS system at FETC/Morgantown was established through telnet. Several modifications to the existing Single Particle Heat Transfer code were made that include option for various input and/or combinations of input for thermal properties such as constant, temperature-dependent, heating rate dependent, and time dependent values. Many sensitivity analyzes were employed to evaluate and quantify the impact of several heat transfer parameters for coal such as thermal properties and heat transfer coefficient, geometry related properties such as shape, mass, and density, and chemical properties such as devolatilization kinetic coefficients on rapid heating. This work improved the model performance of the present work, and also aided in several publications [46-50]. Approval for physical access to the Single Particle Laboratory at FETC/Morgantown from Morgantown facility was obtained. This required completion of several laboratory safety courses by CAU researchers including the PI at the Morgantown site.

Several polystyrene spheres were caught in the electrodynamic balance system at FETC/Morgantown and the operation of the associated system components such as video-based imaging systems, diode-array imaging system, dc and ac power supply, particle position control, and GE tungsten strip lamp \& lens systems for pyrometer were tested and found to be performing well. Completed calibration of several components of the balance measurement system including imaging systems and particle position control system. Also completed was the alignment and calibration of the heating laser to heat coal particles, and the single-color pyrometer to measure particle temperature histories.

Approvals from FETC/Pittsburgh, CAU, and UTRC for performing the heated grid work at Clark Atlanta University (CAU), GA, that was originally planned at United Technologies Research Center (UTRC), CT, were obtained. More recently, donation agreement for the heated grid measurement system from UTRC was obtained, and the shipment of the grid components from UTRC to CAU was complete. Purchase of several instrumentation that were not available in the package from UTRC that include power supply, data acquisition interface, and spot welder was made by CAU. Inspection and testing of the heated grid system components at CAU and sensitivity analyses of the heated grid heat transfer calculations were performed.

Existing laser heating set-up at the Single Particle Laboratory, Federal Energy Technology Center, Morgantown, WV would work only in the range of $10^{4}$ to $10^{5} \mathrm{~K} / \mathrm{s}$. Appropriate changes were made to heat particles in the range of $10^{4}$ to $10^{7} \mathrm{~K} / \mathrm{s}$. For this, power attenuator and the charge voltage of the heating laser system were carefully adjusted, beam path reconfigured and aligned, and the laser power characterized to obtain optimum spatial and temporal distribution.

Dr. Sampath, PI of this project, was at FETC/Morgantown in several visits during the project performance period. He was involved in the alignment and setting up of the pyrometry system. Dr. Sampath is also involved in the reduction of experimental data, modeling activities including sensitivity analyses, comparison with data, and heat transfer analyses. Dr. Esmail Monazam who has coauthored with the PI in a number of publications in the subject matter has been working as a parttime research associate in this project and is stationed at FETC/Morgantown. Dr. Monazam was involved in the experimental activities of this project. 
Calibration for all the components of the electrodynamic balance measurement system including single-color pyrometer and heating laser was successfully completed in the previous reporting periods. Following the calibration, a few coal particles were injected into the balance and by application of ac and dc potentials to the ring and endcap electrodes, a single particle that had a higher charge-to-mass ratio was confined at the null position of the balance. Following the approach of Maloney et al. [21-23], the particle volume, external surface area, mass, and density were measured. The same particle was then heated bidirectionally with a pulsed (10 ms pulse width) Nd:YAG laser beams of equal intensity. Using the approach of Sampath [18-19], the temporal power variation in the laser pulse was monitored for use in the heat transfer analysis by an ultra-fast fiber optic uv light transmitter included in the beam path and coupled to a silicon photodiode. Measurements of changes in particle size that accompanied rapid heating was made by means of the high-speed diode array imaging system. Dynamics of volatile evolution and particle swelling was recorded using well established $[2,5,18]$ time-resolved high-speed cinematography. Measurements of the radiant emissive power from the heated and cooled (when the laser was turned off) particles was made using the single-color pyrometer. Particle experimental temperatures was calculated from the measurements of particle size and radiant emissive power by applying the Wein approximation to Plank's law.

Joie C. Taylor, an undergraduate student in Engineering, was partially supported and trained in the subject matter.

Several theoretical analyses were conducted to improve the model performance of the present work and the results were compared with data available from our previous studies. These activities resulted in one journal publication [47], four conference presentations [46,49-51], and one symposium presentation [48] to date.

A new thermodynamic model was developed to predict the heat transfer behavior for coal particles subjected to a range of heating rates using one approach based on the analogy of polymers. Sensitivity analyses of this model suggest that bituminous coal particles behave like polymers during rapid heating on the order of $10^{4}-10^{7} \mathrm{~K} / \mathrm{s}$. At these heating rates during the early stages within the first few milliseconds of heating time, the vibrational part of the heat capacity of the coal molecules appears to be still frozen but during the transition from heat-up to devolatization, the heat capacity appears to attain a sudden jump in its value as in the case of polymers. There are few data available in the coal literature for $10^{2}-10^{3} \mathrm{~K} / \mathrm{s}$ obtained by UTRC in their previous studies. These data were obtained for a longer heating duration on the order of several seconds as opposed to the 10 milliseconds heating time in the single particle experiments discussed above. The polymer analogy model is being modified to include longer heating time on the order of several seconds to test these data. It is expected that the model might still do a good job in the case of these larger heating time but very low heating rate experiments.

Completion of the numerical analysis of the experimental data and preparation of the final report are in progress. 


\section{OUTCOMES TO DATE}

1. Sampath, R., Monazam, E. R., Maloney, D. J., and Zondlo, J. W., Development of Improved Coal Combustion Modeling: Analysis of Coal Particle Irregularity and Thermal Properties on Temperature Predictions, Fifth Annual HBCU conference organized by FETC/DOE at Southern University and A\&M College, LA, March 1997.

2. Sampath, R., Maloney, D. J., and Monazam, E. R., Effect of Heating Rate on the Thermodynamic Properties of Pulverized Coal, Contractors Review Meeting, Fifth Annual HBCU conference organized by FETC/DOE at Southern University and A\&M College, LA, March 1997.

3. Taylor, J. C., Sampath, R., Maloney, D. J., Zondlo, J. W., and Monazam, E. R., Transport Phenomena of Irregularly-Shaped Solid Particles in an Electrodynamic Balance, Poster Paper, Fifth Annual DOE/HBCU conference, Southern University and A\&M College, LA, March 1997.

4. Sampath, R., Maloney, D. J., Zondlo, J. W., and Monazam, E. R., Temperature Histories for Single Coal Particles Prior to Devolatilization, Central States Technical Meeting, Combustion Institute, April 1997, Point Clear, AL.

5. Taylor, J. C., Sampath, R., and Maloney, D. J., Characterization of Small Single Particles in an Electrodynamic Balance, Annual Student Scientific Research Symposium, April 15, 1997, Clark Atlanta University, Atlanta, GA.

6. Sampath, R., Maloney, D. J., Zondlo, J. W., and Monazam, E. R., Evaluation of Errors Resulting From Nusselt Number Assumptions in Coal Combustion Modeling, Paper No. DETC97/CIE-4519, 1997 ASME Design Engineering Technical Conferences, September 14-17, 1997, Sacramento, CA.

7. Sampath, R., Maloney, D. J., and Proscia, W., Thermal Property Data for Coal Particles for Use in Rapid Devolatilization Models, Technology Transfer Session, Historically Black Colleges/Universities and Other Minority Institutions Sixth Annual Symposium, April 28-29, 1998, Ocean City, MD.

8. Taylor, J., Sampath, R., Maloney, D. J., and Proscia, W., Rapid Devolatilization Studies for Coal Particles in an Electrodynamic Balance and in a Heated Grid Reactor, Technology Transfer Session, Historically Black Colleges/Universities and Other Minority Institutions Sixth Annual Symposium, April 28-29, 1998, Ocean City, MD.

9. Sampath, R., Maloney, D. J., and Zondlo, J. W., Measurements of Surface Area and Volume for Irregularly-Shaped Coal Particles, Central States Technical Meeting, Combustion Institute, 31 May - 2 June, 1998, Lexington, KY.

10. Sampath, R., Maloney, D. J., and Zondlo, J. W., Evaluation of Thermophysical and Thermochemical Heat Requirements for Coals at Combustion Level Heat Fluxes, 27th International 
Symposium on Combustion, August 2-7, 1998, Boulder, CO.

11. Maloney, D. J., Sampath, R., and Zondlo, J. W., Heat Capacity and Thermal Conductivity Considerations for Coal Particles During the Early Stages of Rapid Heating, Combustion and Flame 116:94-104 (1999).

12. Sampath, R., Monazam, E. R., and Maloney, D. J., Devolatilization Temperature Histories for Coal Particles Subjected to Combustion Level Heat Fluxes, Technology Transfer Session, Historically Black Colleges/Universities and Other Minority Institutions Seventh Annual Symposium, April 1999, Miami, FL.

\section{WORK PERFORMED DURING THIS REPORTING PERIOD}

The performance period for the coal project ended by September 23, 1999. The final report is due by December 23, 1999. The experiments were completed, model developed and tested to be found okay. Data reduction and analysis are in progress. Preparation of the final report is also in progress.

Collection and reduction of experimental data for a total of 28 single coal particles ( 8 more than what was originally planned) using the Single Particle Laboratory, FETC's Morgantown facility was completed during this reporting period. A TTL pulse was used to start the high-speed movie camera with a time delay and when the delay time is reached the movie camera achieved a filming rate of about 5000 frames per second, synchronizingly the heating laser was started and particle zapped and high-speed data acquisition including transient temperature history measurement using optical pyrometer commenced.

A new thermodynamic model was developed during this reporting period to predict the heat transfer behavior for coal particles subjected to a range of heating rates using one approach based on the analogy of polymers. This model assumed a 'sudden jump' in the heat capacity of coal from its room temperature value to Merrick's model [25] temperature-dependent values once devolatilization (mass loss) begins. This approach is analogous to the heat capacity data of polymers that undergo phase changes [30]. If one looks at temperature-specific heat data of polymers, it is apparent that there is nearly a discontinuous change in their specific heat as they undergo phase change from solid to glass transition [30]. The glass transition temperature of a polymer is defined as the temperature below which an amorphous polymer (or an amorphous region of a crystalline polymer) is rigid and brittle (glassy) and above which it is rubbery or fluid like [30]. The sudden change in specific heat of a polymer with phase change is attributed to an increase in the degrees of freedom available to the functional groups of the polymeric material [30]. The specific volume of the polymers increases linearly with temperature up to the glass transition temperature after which the specific volume continues to increase linearly but at a steeper gradient [30]. The glass transition phenomena with increase in specific volume observed in polymers can be viewed as similar to the metaplast phenomena with swelling seen in plastic coals during devolatilization. High-speed films showed that swelling is accompanied with onset of particle rotation or commencement of light volatile evolution in coal particles. In other words, commencement of light volatile evolution in coal particles can be viewed 
as an indication of phase change in coal particles from solid to plastic. Thus the phase change from glassy (solid) to rubbery in polymers is analogous to the phase change from solid state to plastic state (swelling with volatile evolution) in bituminous coals. The polymers go through a sudden jump in their heat capacity during the phase change from glassy to rubbery. Thus, the bituminous coal particle in the present heat transfer analysis is assumed to display analogous behavior in its heat capacity from the average room temperature value to temperature-dependent value once mass loss begins (when $t=t_{0.1 \%}$ ). Thermal conductivity of the polymers goes through rather a flat maximum at glass transition temperature and remain fairly constant in the rubbery region [30]. Since, there is not much change in the thermal conductivity data for polymers from glassy to rubbery, thus, analogous to polymers, the thermal conductivity of the coal particles here is assumed to remain constant in the average room temperature value from the solid state to plastic during devolatilization. With this assumption, the energy conservation equation becomes as follows:

$$
\begin{array}{r}
\mathbf{P}_{p}(t) C_{p} \frac{\partial T}{\partial t}-K_{p}\left(\frac{\partial^{2} T}{\partial r^{2}}+\frac{2}{r} \frac{\partial T}{\partial r}\right)-\left(-\frac{\partial \mathbf{p}_{p}(t)}{\partial t}\right) \Delta H_{d} \\
\text { For } \mathrm{t}<\mathrm{t}_{0.1 \%}, \mathrm{C}_{\mathrm{p}}=\mathrm{C}_{\mathrm{p}}=0.25 \mathrm{cal} / \mathrm{gm} \mathrm{K} \\
\text { For } \mathrm{t}>\mathrm{t}_{0.1 \%}, \mathrm{C}_{\mathrm{p}}=\mathrm{f}(\mathrm{T})=\mathrm{C}_{\mathrm{p}}(\mathrm{T}) \text { Merrick } \\
\text { For all } t, \mathrm{~K}_{\mathrm{p}}=\mathrm{K}_{\mathrm{pc}}=0.0005 \mathrm{cal} / \mathrm{cm} \mathrm{s} \mathrm{K.}
\end{array}
$$

Sensitivity analyses of this model suggest that bituminous coal particles behave like polymers during rapid heating on the order of $10^{4}-10^{7} \mathrm{~K} / \mathrm{s}$. The model prediction was first verified with data available in our previous studies, and then subjected to comparison with the present data. The results are very excited and a paper to the 28th International Symposium on Combustion due by the end of December is in progress $[2,18]$.

UTRC finally donated a number of components of its heated grid reactor to CAU after a long negotiation between CAU and UTRC on to loan or donate. The grid was put together at CAU and started testing the system in the last several months. It was noticed the temperature of the heated grid did not correlate with the rate of heating power input. Several attempts to correct this problem including the rearrangement of power supply circuit input did not help. A crack in the reactor in which the heated grid is housed was noticed and this crack could be a problem for the poor heat load. Attempts to fix this crack would be expensive (no money was budgeted for this kind of problem and no money available) and time consuming and since the project completion date was already near, it was decided to use the heated grid data available in the literature. This approach was discussed with the Technical Monitor, FETC, Pittsburgh. It was originally proposed to collect low heating rate (on the order of $10^{2}-10^{4} \mathrm{~K} / \mathrm{s}$ ) data using the heated grid reactor. There are few data available in the coal literature for $10^{2}-10^{4} \mathrm{~K} / \mathrm{s}$ obtained by UTRC in their previous studies. Data for $10^{4} \mathrm{~K} / \mathrm{s}$ heating rate are available in our previous studies using lasers. While still the scope of the entire proposal remains the same covering the heating rate of $10^{2}-10^{7} \mathrm{~K} / \mathrm{s}$, the polymer analogy model discussed above is being applied to predict the heated grid data. These data were obtained for a longer heating duration on the order of several seconds as opposed to the 10 milliseconds heating time in the single particle experiments discussed above. So, the polymer analogy model is being modified to include longer heating time on the order of several seconds to test these data. It is expected the polymer analog 
model might still do a good job in the case of very low heating rate experiments such as the ones from heated grid, but it is not sure yet. UTRC has no problem with our approach of using their data as these data are already available in the public domain/literature [9-10].

\section{PLANS FOR THE FINAL REPORT}

It is expected that the data reduction and numerical analyses will be completed within the month of November 1999. Development of the final report is in progress. It is highly hoped that the final report will be submitted within the due date of December 23, 1999.

\section{SUMMARY AND CONCLUSIONS}

A new thermodynamic model was developed during this reporting period to predict the heat transfer behavior for coal particles using one approach based on the analogy of polymers. Sensitivity analyses of this model suggest that bituminous coal particles behave like polymers during rapid heating on the order of $10^{4}-10^{7} \mathrm{~K} / \mathrm{s}$. At these heating rates during the early stages within the first few milliseconds of heating time, the vibrational part of the heat capacity of the coal molecules appears to be still frozen but during the transition from heat-up to devolatization, the heat capacity appears to attain a sudden jump in its value as in the case of polymers. Completion of the numerical analysis of the experimental data and preparation of the final report are in progress.

\section{ACKNOWLEDGMENTS}

The project is supported by FETC/Pittsburgh under Grant No. DE-FG22-96PC96224. Technical discussions provided by Dr. Mildred B. Perry are also gratefully acknowledged and appreciated.

\section{REFERENCES}

1. Fletcher, T. H., Time-resolved temperature measurements of individual coal particles during devolatilization, 1989. Combust. Sci. and Tech. 63, 89.

2. Maloney, D. J., E. R. Monazam, S. W. Woodruff, and L. O. Lawson., Measurement and analysis of temperature histories and size changes for single carbon and coal particles during the early stages of heating and devolatilization, 1991. Combustion and Flame 84: 210-220.

3. Solomon, P. R., M. A. Serio, R. M. Carangelo, and J. R. Markham., 1986. Fuel 65, 182.

4. Tichenor, D. A., Mitchell, R. E., Hencken, K. R., and Niksa, S., Simultaneous in situ measurement of the size, temperature and velocity of particles in a combustion environment, Twentieth Symposium (International) on Combustion, p. 1213, The Combustion Institute, 1985.

5. Phouc, T. X. and D. J. Maloney, Laser Pyrolysis of single coal particles in an electrodynamic balance, Twenty-Second Symposium (International) on Combustion, 1988/pp. 125-134. 
6. Solomon, P. R., Serio, M. A., and E. M. Suuberg, Coal pyrolysis: experiments, kinetic rates and mechanisms, Prog. Energy Combust. Sci. 1992, Vol. 18, p. 142.

7. Niksa, S. 1986. The Distributed Energy Chain Model for Rapid Coal Devolatilization Kinetics, Part II: Transient Weight Loss Correlations, Comb. Flame, 66, 111.

8. Serio, M. A., P. R. Solomon, D. G. Hamblen, J. R. Markham, and R. A. Carangelo. Coal Pyrolysis Kinetics and Heat Transfer in Three Reactors. Twenty-first Symposium (International) on Combustion, 1986. Combustion Inst., Pittsburgh, PA, 1986, p. 153.

9. Freihaut, J. D., and W. M. Proscia. 1989. Tar Evolution in heated-grid apparatus, Energy and Fuels, 3, 625 .

10. Freihaut, J. D., Zabielski, M. F. and D. J. Seery. A parametric investigation of tar release in coal devolatilization, Nineteenth Symposium (International) on Combustion/The Combustion Institute, 1982/pp. 1159-1167.

11. Fletcher, T. H. Time-resolved particle temperature and mass loss measurements of a bituminous coal during devolatilization, 1989. Combustion and Flame, 78, pp. 223-236.

12. Badzioch, S., and P. G. W. Hawksley. 1970. Kinetics of Thermal Decomposition of Pulverized Coal Particles, Ind. Eng. Chem., 9, 521.

13. Kobayashi, H., J. B. Howard, and A. F. Sarofim. Coal devolatilization at high temperatures, 1976. 16th Symposium (International) on Combustion, pp. 411-425.

14. Hertzberg, M., I. A. Zlochower, and J. C. Edwards. Coal particle pyrolysis mechanisms and temperatures, 1988. Bureau of Mines Report of Investigations, United States Department of the Interior, Pittsburgh, Pennsylvania.

15. Hertzberg, M. and I. A. Zlochower. Devolatilization wave structures and temperatures for the pyrolysis of Polymethylmethacrylate, Ammonium Perchlorate, and Coal at combustion level heat fluxes, Combustion and Flame 84: 15-37 (1991).

16. Peters, W. and Bertling, H. Kinetics of the rapid degasification of coals, Fuel 44, p. 317 - 331, (1965).

17. Saxena, S. C. Devolatilization and combustion characteristics of coal particles, Prog. Energy Combust. Sci. 1990, Vol. 16, pp. 55-94.

18. Sampath, R. (1994), Measurement and Prediction of Temperature Histories for Single Coal Particles Prior to and During Devolatilization, Ph.D. Thesis, Department of Chemical Engineering, West Virginia University, Morgantown. 
19. Sampath, R., Maloney, D. J., Zondlo, J. W., Woodruff, S. D., and Y. D. Yeboah, Measurements of Coal Particle Shape, Mass and Temperature Histories: Impact of Particle Irregularity on Temperature Predictions and Measurements, 26th Symposium (International) on Combustion/The Combustion Institute, Naples, Italy, July 1996.

20. Rosin, P. O., The influence of particle size in processes of fuel technology, Trans. Inst. Chem. Engrs., 15: 167 (1937).

21. Monazam, E. R. and D. J. Maloney, Characterization of mass and density distributions of sized coal fractions, Twenty-Fifth Symposium (International) on Combustion, 1994.

22. Maloney, D. J., Lawson, L. O., Fasching, G. E., and Monazam, E. R., A novel approach for determining external surface area and volume of irregularly shaped particles, Aerosol Sci. Technol. 22:60-72 (1995).

23. Maloney, D. J., Lawson, L. O., Fasching, G. E., and Monazam, E. R., Measurement and dynamic simulation of particle trajectories in an electrodynamic balance: characterization of particle drag coefficient/mass ratios, Rev. Sci. Instrum. 66:3615-3622 (1995).

24. Maloney, D. J., Monazam, E. R., Sampath, R., and Dodoo, J. N., An assessment of particle shape and thermal property data: implications for coal combustion modeling, 1990 Fall Technical meeting, Eastern Section of the Combustion Institute, December 3-5, Orlando, FL, Paper No. 91.

25. Merrick, D. 1983. Mathematical models of the thermal decomposition of coal, 2. Specific heats and heats of reaction, Fuel, 62, p. 540-546.

26. Badzioch, S., D. R. Gregory, and M. A. Field. 1964. Investigation of the temperature variation of the thermal conductivity and thermal diffusivity of coal, Fuel, 43, 267.

27. Monazam, E. R. and D. J. Maloney, Temperature transients associated with pulsed heating of single particles, J. Appl. Phys. 71 (6), 1992.

28. Maloney, D. J., Monazam, E. R., and Sampath, R., Evaluation of errors resulting from particle shape assumptions applied in coal combustion modeling, Int. Conf. Coal Sci., Newcastle, UK, Sept. (1991).

29. Kirov, N. Y. 1965. Specific heats and total heat contents of coals and related materials at elevated temperatures, B.C.U.R.A. Monthly Bull., Review No. 241, p.33-57.

30. Van Krevelen, D. W. and Hoftyzer, P. J., Properties of Polymers, Elsevier Sci. Publishing Company, New York, 1976.

31. Singer, J. M., and R. P. Tye. 1979. Thermal, mechanical, and physical properties of selected bituminous coals and cokes, U.S. Bureau of Mines Report of Investigations No. 8364, pp. 37. 
32. MacDonald, R. A., J. E. Callanan, and K. M. McDermott. 1987. Heat capacity of a mediumvolatile bituminous premium coal from 300 to $520 \mathrm{~K}$. Comparison with a high-volatile bituminous nonpremium coal, Energy and Fuel, 1, 535.

33. Badzioch, S. 1960. Thermo-physical properties of coals and cokes, B.C.U.R.A. Monthly Bull., 24, 485-520.

34 Kasperczyk, J. and Simonis, W., Gulkauf-Forschungshefte, 1971, vol. 32, pp. 23.

35. Agroskin, A. A., Goncharov, E. I. and Grayaznov, N. S., Coke and Chemistry (Eng. Trans. 1972, vol. 9, pp. 3-5.

36. Monazam, E. R., D. J. Maloney, L. O. Lawson. 1989. Measurement of heat capacities, temperatures, and absorptivities of single particles, Rev. Sci. Instrum. 60, 3460.

37. Howard, J. B. 1981. Chemistry of Coal Utilization (M. A. Elliot, ed.) Second Supplementary Volume, p. 665-784, John Wiley \& Sons, New York.

38. Solomon, P. R., and D. G. Hamblen. 1985. Chemistry of Coal Conversion (R. H. Schlosberg, ed) pp. 121-251, Plenum Press.

39. Bliek, A., Poelje, W. M., Swaaij, W. P. M., and F. P. H. Beckum, Effects of intra-particle heat and mass transfer during devolatilization of a single coal particle, AIChE Journal (Vol. 31, No. 10), p.1666-1681, 1985.

40. Tomeczek, J. and Kowol, J. Temperature field within a devolatilizing coal particle, The Canadian Journal of Chemical Engineering, vol 69, p. 286-293, (1991).

41. Ardent, P., and van Heek, K-H., Comparative Investigations of Coal Pyrolysis under Inert Gas and $\mathrm{H}_{2}$ at Low and High Heating Rates and Pressures up to 10MPa, Fuel 1981, Vol. 60, pp. 779.

42. Wagner, R., Wanzl, W., and van Heek, K-H., Influence of Transport Effects on Pyrolysis Reaction of Coal at High Heating Rates, Fuel 1985, Vol. 64, pp. 571.

43. Niksa, S., Heyd, L. E., Russel, W. B., and Saville, D. A., On the Role of Heating Rate in Rapid Coal Devolatilization, 20th Symposium (International) on Combustion, The Combustion Institute, Pittsburgh, Pennsylvania, 1984/pp. 1445-1453.

44. Yurum, Y., Karabakan, A. K., and Altuntas, N., Effect of Heating Rate on Glass Transition Temperature of Zonguldak Bituminous Coal, Energy \& Fuels 1991, 5, 701-703.

45. Juntgen, H., and van Heek, K-H., Gas Release from Coal as a Function of the Rate of Heating, Gordon Research Conference on Coal Science, New Hampshire, July 1967. 
46. Sampath, R., Maloney, D. J., and Zondlo, J. W., Measurements of Surface Area and Volume for Irregularly-Shaped Coal Particles, Central States Technical Meeting, Combustion Institute, 31 May - 2 June, 1998, Lexington, KY.

47. Maloney, D. J., Sampath, R., and Zondlo, J. W., Heat Capacity and Thermal Conductivity Considerations for Coal Particles During the Early Stages of Rapid Heating, Combustion and Flame 116:94-104 (1999).

48. Sampath, R., Maloney, D. J., and Zondlo, J. W., Evaluation of Thermophysical and Thermochemical Heat Requirements for Coals at Combustion Level Heat Fluxes, 27th International Symposium on Combustion, August 2-7, 1998, Boulder, CO.

49. Sampath, R., Maloney, D. J., and Proscia, W., Thermal Property Data for Coal Particles for Use in Rapid Devolatilization Models, Technology Transfer Session, Historically Black Colleges/Universities and Other Minority Institutions Annual Symposium, April 28-29, 1998, Ocean City, MD.

50. Taylor, J., Sampath, R., Maloney, D. J., and Proscia, W., Rapid Devolatilization Studies for Coal Particles in an Electrodynamic Balance and in a Heated Grid Reactor, Technology Transfer Session, Historically Black Colleges/Universities and Other Minority Institutions Annual Symposium, April 28-29, 1998, Ocean City, MD.

51. Sampath, R., Monazam, E. R., and Maloney, D. J., Devolatilization Temperature Histories for Coal Particles Subjected to Combustion Level Heat Fluxes, Technology Transfer Session, Historically Black Colleges/Universities and Other Minority Institutions Seventh Annual Symposium, April 1999, Miami, FL. 